\title{
PRELIMINARY INVESTIGATION ON THE PHYSIOLOGY AND ECOLOGY OF LUMINESCENCE IN THE COPEPOD, METRIDIA LUCENS ${ }^{1}$
}

\author{
CHARLES N. DAVID AND ROBERT J. CONOVER
}

\author{
Harzard College, Cambridge, Mass., and Woods Hole Oceanographic Institution, \\ Woods Hole, Mass.
}

Since the advent of the photomultiplier tube with greatly increased sensitivity to low light intensity, it has been possible to measure marine luminescence quantitatively. Luminescent flashes have been found to be far more prevalent at all depths in the sea than had generally been suspected (Clarke and Backus, 1956; Clarke and Breslau, 1959, 1960; Clarke and Hubbard, 1959; Clarke and Wertheim, 1956; Boden and Kampa, 1957, 1958; Kampa and Boden, 1957). Attempts to identify the source of this flashing, using the luminescence camera built by Breslau and Edgerton (1958), suggest that most of the luminescence is produced by planktonic organisms less than a centimeter long (Clarke and Breslau, 1959; Clarke, personal communication). Certain planktonic species whose luminescence has been investigated do not show spontaneous luminescence in the laboratory. Probably some of the luminescence which has been measured at sea may be artificially stimulated by the unavoidable motion of the photometer suspended from a research vessel. However, Kampa and Boden (1957) have concluded that some luminescence appears to be "natural" or "spontaneous."

Bioluminescence in a small planktonic animal has been examined particularly with a view toward evaluating its potential as a source of luminescence in the natural environment and determining the significance of the luminescence for the organism. The calanoid copepod, Metridia lucens, was the animal chosen.

This copepod was recognized as luminescent by Boeck (1865) who described the species. Several additional workers have made microscopic or field observations on the luminescent Copepoda (Dahl, 1893, 1894; Kiernik, 1908; Vanhöffen, 1895 ; Giesbrecht, 1895), but very little experimental work has been done.

In the present work preliminary investigation of certain physical properties of the luminescent emission and of the physiology of the luminescent mechanism has been attempted, in addition to the experiments designed to ascertain what ecological significance luminescence may have for this copepod.

The authors are indebted to Dr. George L. Clarke for his advice and criticism in planning the work and in the preparation of the manuscript. The authors also wish to express their thanks to Dr. W. D. McElroy, Dr. James F. Case, Dr. Edward R. Baylor and members of the staff of the Woods Hole Oceanographic Institution for their cooperation and assistance.

${ }^{1}$ Contribution No. 1183 from the Woods Hole Oceanographic Institution. Research supported by National Science Foundation Grants 3838 and 8913. 


\section{Materials and Methods}

The copepods used in the experiment were obtained in Cape Cod Bay about 3-5 miles northeast of the mouth of the Cape Cod Canal in 20-30 m. of water. Collections were made on two occasions, July 7 and August 16, 1960, with a 3/4-meter \#00 plankton net towed near the bottom. The Metridia were isolated from the catch and maintained in the laboratory approximately 40 animals to $1000 \mathrm{ml}$. of food culture. Laboratory cultures of the diatom Thalassiosira fluviatilis were used as food diluted 1:20 by volume with millipore-filtered sea water from Cape Cod Bay. This gave a concentration of 6000 to 10,000 cells $/ \mathrm{ml}$. in the final food culture.

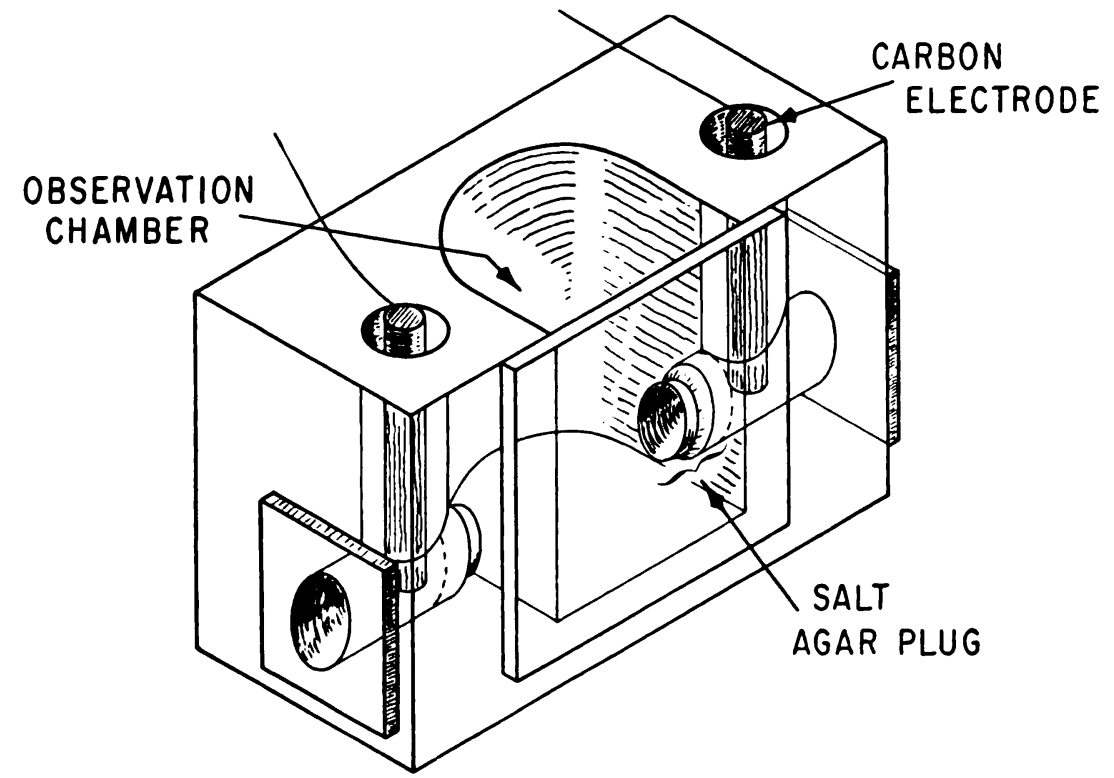

Figure 1. Electrode chamber used for stimulation of Metridia. For details see text.

Either streptomycin or penicillin $(50 \mathrm{mg}$./1.) was added to inhibit bacterial growth. For specific experiments, smaller groups of Metridia were kept in proportionately smaller volumes of food medium. All groups of animals were kept in a darkened refrigerator at $5-7^{\circ} \mathrm{C}$.

Measurements of luminescence were made in a "black box" consisting of a tarpaper covered wooden frame built on top of a table. A large opening on one side of the box covered with a black cloth sleeve and drawstring permitted the investigator's head to remain inside the box for observations or to monitor recording and stimulating instruments outside the box.

The measurements of luminescence were made with the portable bathyphotometer designed and built by Breslau (1959), which employs a RCA 5819 photomultiplier tube with $1200 \mathrm{v}$. battery power and a transistor amplifier circuit. Experimental material was placed directly in front of the photomultiplier about 18 $\mathrm{cm}$. from the sensitive surface. A Texas Instruments, Inc. single-channel, stripchart recorder ("Recti/Riter") was used to record intensity (in $\mu \mathrm{w} . / \mathrm{cm}^{2}{ }^{2}$ ) against time during each flash. 
Since the Metridia do not generally luminesce spontaneously in the laboratory, mechanical or electrical stimulation must be applied to study the characteristics of the flashing. In order to standardize the stimulus delivered to the animals, a simple electrode chamber was constructed as shown in Figure 1. The device was cut out of a piece of lucite and the connecting holes between the two side chambers and the central chamber were filled with $3 \%$ agar made with millipore-filtered sea water. For experiments, carbon electrodes wired to a pulse regulator were placed in the side chambers and the whole device was filled with cooled sea water to complete the circuit. Metridia, either individually or in groups, were then placed in the central chamber for stimulation.

All stimulation was performed with alternating current controlled through an electronic switch and a continuously adjustable autotransformer, Variac Type W10MT. The switch regulated the duration of pulses to one-tenth of a second and the interval between pulses to two-tenths of a second. Although slightly sensitive to changes in salinity and temperature, the current was regulated accurately to one-tenth of an ampere. The chart speed of the recorder was varied for different experiments. The slower speed $(6 \mathrm{in} . / \mathrm{hr}$.) was used to record the frequency and intensity of flashes. The faster speeds ( 6 or $12 \mathrm{in.} / \mathrm{min}$.) were used when a measure of total luminescent flux (area under intensity curve) or the duration of a flash was required.

\section{Description and Distribution of Metridia lucens}

Metridia lucens is a medium-sized copepod, virtually colorless in the living state. Its size varies between $2.4-3.0 \mathrm{~mm}$. for females and $1.8-2.5 \mathrm{~mm}$. for males.

Although Metridia lucens is a common copepod of temperate and boreal water, very little is known regarding its seasonal abundance or life-history. In the Gulf of Maine, Bigelow (1924) noted an increased abundance in the spring and again in September and October. Bigelow (1924) and Clarke (1933, 1934) observed extensive diurnal vertical migrations in this species. In the waters off the coast of Ireland it also seemed to have a period of maximum abundance in May and a smaller period of increase in the fall (Farran, 1920). During the spring it has been reported to be responsible for brilliant phosphorescence on the Irish coast (Farran, 1903, in Bigelow, 1924).

Little is known regarding the internal anatomy of the copepods. Among the calanoids only Calanus finmarchicus has been studied in detail (by Lowe, 1935). It is presumed that in the general features of its morphology Metridia does not differ greatly from Calanus although there doubtless are certain differences in structural detail.

The only light-sensitive organ in most copepods, including Metridia, is a single naupliar eye. It seems very doutbful that this organ can have any role in behavior requiring recognition of other organisms because it cannot form images. However, it can presumably detect intensity gradients (as in vertical migration) and possibly the plane of polarization of incident light.

\section{Luminescent glands}

The earliest workers recognized that the luminescence produced by Metridia was primarily external. Boeck (1865), who described Metridia lucens, noted that 
the light seemed to be produced in the head region and also from the abdomen. Vanhöffen (1895), working with the larger $M$. longa, observed luminescence distributed over most of the thorax as well as the head. In addition to the external secretion, he also felt that some light was produced internally which indicated the position of the secretory glands.

The authors observed that Metridia lucens seemed to produce luminescence, when stimulated electrically, chiefly from the anterior part of the head and from the region of the caudal rami. The separation of these two regions was sufficiently distinct that the light produced persisted sometimes as two discrete points for some seconds.
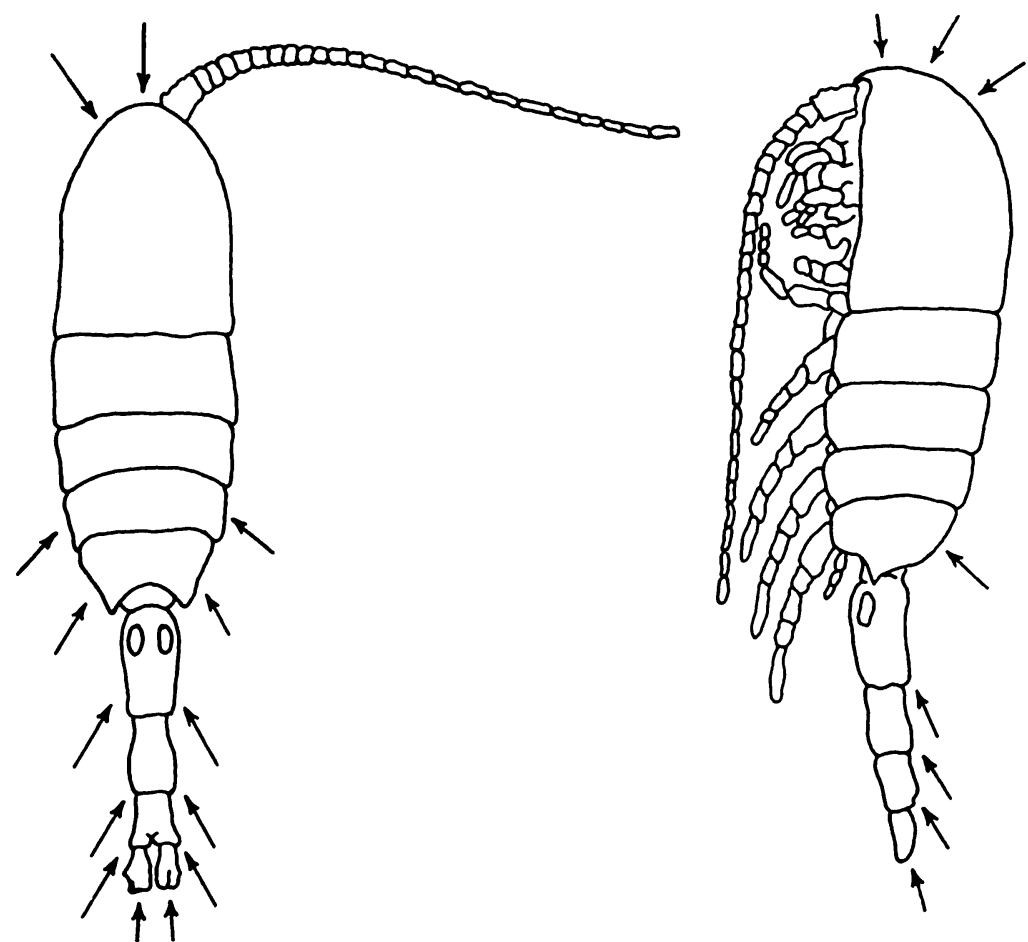

Figcre 2. Mctridia lucens: left, a dorsal view: right, a lateral view. Arrows indicate the general regions of the body where luminescent glands were found.

Due to the kindness of Dr. Robert Hessler, some histological preparations of Metridia lucens, fixed in Zenker's and stained with hematoxylin and eosin were available for study of the glands and their distribution. Figure 2 shows the regions of the body seen microscopically to produce luminescence in observations on living animals. Glands were located in the histological preparations in most of these places with definite concentrations on the anterior surface of the head and on the posterior portion of the abdomen.

The glands varied in shape somewhat depending on their location in the body. Those in the urosome had a long connecting duct between the glands and the external pore while those in the thorax opened directly to the outside through a 
short duct. In several cases masses of dark material which might be the luminescent substance were observed in these ducts.

Sewell $(1932,1947)$ describes the presence of external pores on the cuticle, presumably associated with glandular structures, in several groups of copepods including Metridia. It is not certain, however, that these are the openings to

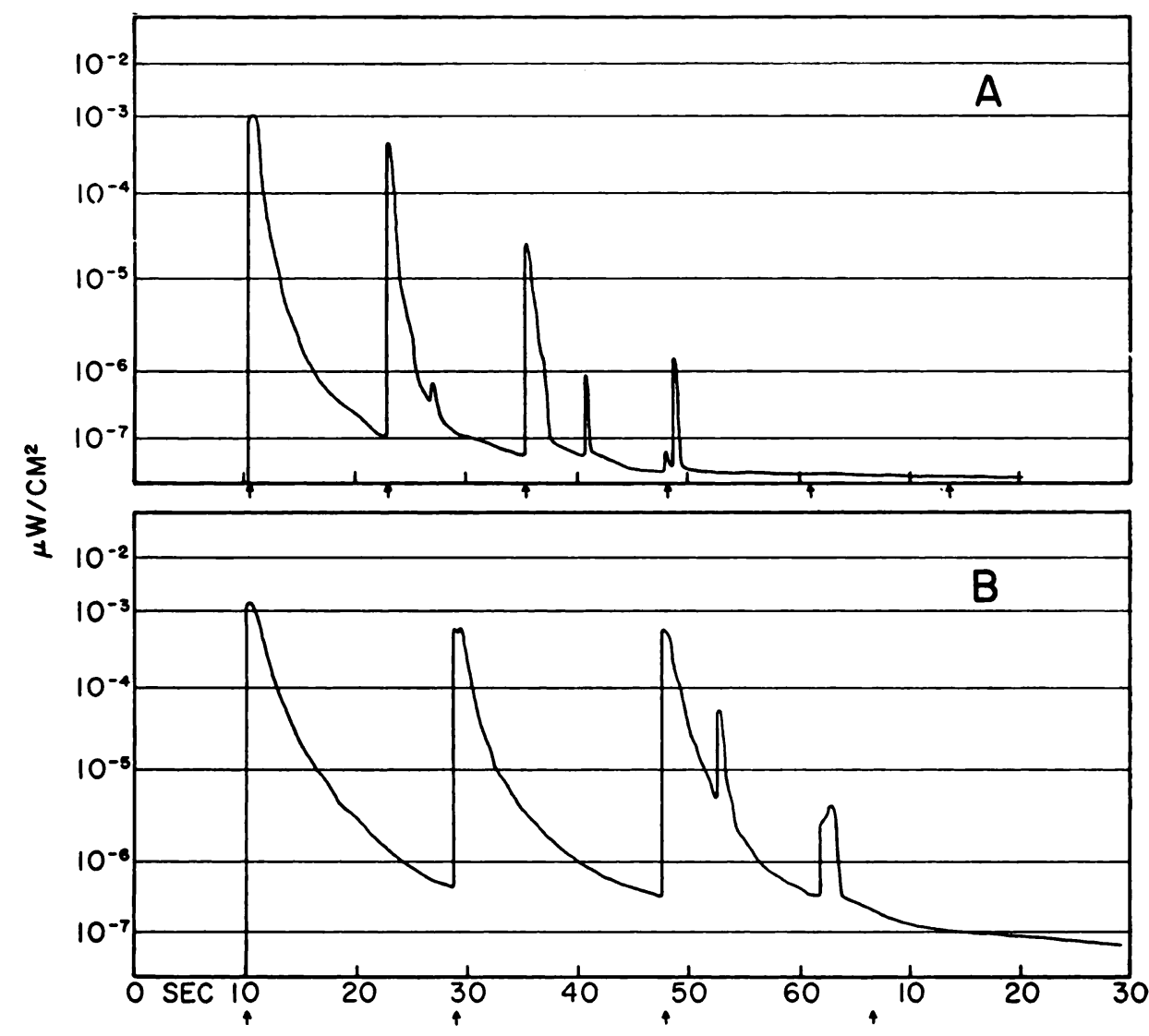

Figure 3. Luminescence of single Metridia when stimulated in the electrode chamber. Arrows along the time scale indicate instant of stimulation $(0.7 \mathrm{amp}$. $)$. Chart speed is $6 \mathrm{in} . / \mathrm{min}$. $A$ shows curve for an animal tested six hours after capture; $B$ shows curve for an animal tested after being kept in the laboratory for one month.

luminescent glands, particularly since such structures are found in several genera not presently known to be luminescent, notably Eucalanus and Temora. The distribution of these pores has not been worked out in detail for Metridia lucens.

\section{Physical characteristics of the luminescence}

The luminescent emission of Metridia lucens is generally a bright flash of varying duration. According to Harvey (1952), luminescence in copepods results from the simultaneous discharge of substrate and enzyme into the surrounding 
medium; presumably the immediate peak emission occurs at the instant of initial contact between the reacting substances in the presence of oxygen. Generally a gradual decay follows as enzyme and substrate diffuse away into the medium, or perhaps as the substrate is used up.

The absolute intensity of the highest peak of the luminescent emission is in doubt because of the relatively slow response time of the equipment used. Furthermore, the maximum emission intensity varied to some extent for individual animals. However, the maximum intensity measured for Metridia was $1.2 \times 10^{-3} \mu \mathrm{w} . / \mathrm{cm} .{ }^{2}$

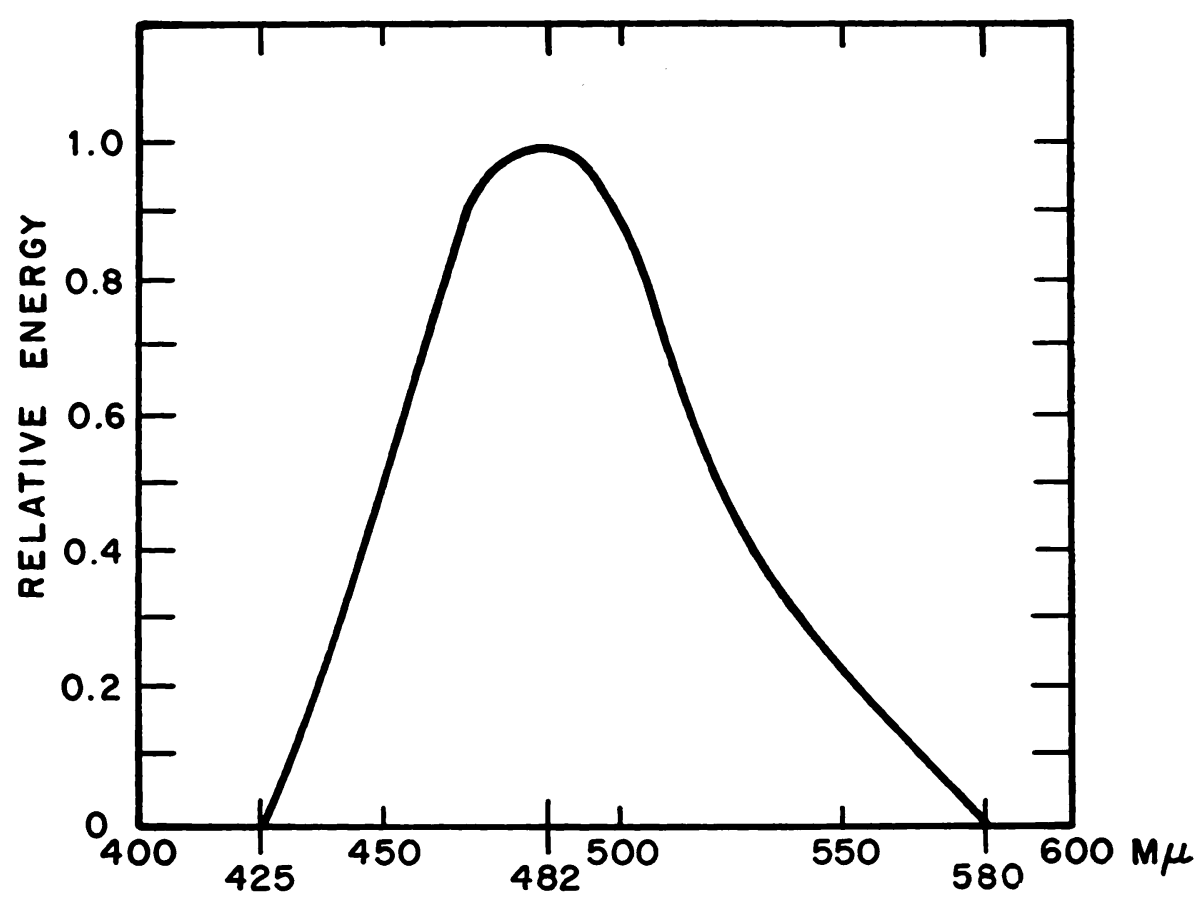

Figure 4. Spectrum of luminescent emission at $0^{\circ} \mathrm{C}$. from crushed animals.

at the working distance of $18 \mathrm{~cm}$. (Fig. 3). With groups of 5 Metridia, there was an additive effect giving maximum intensities of up to $4.5 \times 10^{-3}$. The intensity of the response decreased after successive stimuli.

The duration of individual responses varied even more widely than the maximum intensities, and ranged from 3 seconds to 50 seconds for all luminescent responses with intensities between $10^{-3}$ and $10^{-4} \mu \mathrm{w} . / \mathrm{cm}^{2}$. There was no apparent relationship between the intensity of a luminescent emission and its duration. For example, two Metridia, exactly similar in laboratory history, both gave responses of $3 \times 10^{-4} \mu \mathrm{w} . / \mathrm{cm} .^{2}$, one emission having a duration of 10 seconds, the other a duration of 50 seconds. If responses of a lower maximum intensity than $10^{-4} \mu \mathrm{w} . / \mathrm{cm} .^{2}$ are considered, durations as short as 1 second have been measured, particularly at the end of fatigue experiments when the Metridia had already responded to 10 or 15 electrical stimuli. 
Through the kindness of Dr. W. D. McElroy at the Marine Biological Laboratory, Woods Hole, Massachusetts, it was possible to measure the spectrum of Metridia's luminescent emission (Fig. 4). The apparatus used was an Aminco spectrophotofluorometer in circuit with a drum recorder (" $x-y$ " recorder) and an oscilloscope. Because of the rapid decay in intensity of Metridia's luminescence, it was necessary to cool a number of the animals in crushed ice in order to slow down the enzyme reaction producing the luminescence. Then, by immediately crushing the animals in a small test tube directly in the spectrophotofluorometer, the luminescence remained at one intensity long enough to record the entire spectrum.

The peak of the spectrum for Metridia is around $482 \mathrm{~m} \mu$ and is therefore similar to that of Cypridina and certain other luminescent Crustacea (Nicol, 1960). The curve is slightly skewed toward longer wave-lengths with about half the spectral energy falling in the range between $440 \mathrm{~m} \mu$ and $525 \mathrm{~m} \mu$. The entire spectrum lies between $425 \mathrm{~m} \mu$ and $580 \mathrm{~m} \mu$. This spectrum with its peak at $482 \mathrm{~m} \mu$ coincides closely with the wave-lengths having maximum transmission through clear, oceanic sea water (Clarke, Chap. 6, 1954).

\section{Experiments on physiology}

In order to determine whether laboratory culture had any effect on the luminescence of Metridia, freshly captured specimens and some which had been maintained in the laboratory for a month were repeatedly stimulated until failure to respond to two successive stimuli indicated the onset of fatigue. A representative experiment shown in Figure 3 indicates that the maximum intensity and the rate of fatigue were not markedly different for the two specimens. The difference in flash duration is not significant considering the wide range of variation shown by this characteristic.

To study the effect of strength of the stimulating pulse on the luminescence, the current was increased from $.3 \mathrm{amp}$. to $.7 \mathrm{amp}$. which caused a significant increase in the intensity of the luminescence and in the number of responses to stimuli. However, pulses stronger than $.7 \mathrm{amp}$. did not cause further increase in luminescence intensity but seemed to reduce the number of successive responses. Variations in the duration of the pulse over the range tested (.10-1.0 second) had little effect on the intensity or number of successive responses. However, short intervals, i.e., 3 seconds, between pulses induced two or three times as many successive responses as were observed using longer intervals between pulses, i.e., $10-45$ seconds.

The effect of previous light- or dark-adaptation was tested with separate groups of animals kept at about $5^{\circ} \mathrm{C}$. in the dark, in the light, and in a room exposed to diurnal light changes. The experiment was begun at 1700 on August 3 and the luminescence produced by each group was tested on August 5 and again on August 8 between 1000-1300. No statistically detectable difference was found between the three sets of animals. In another experiment twenty animals kept in a water bath at $5^{\circ} \mathrm{C}$., where they were exposed to daily light variation, were tested at night (2330-0030) and during the day $(1300-1400)$. In the case of a few animals the day-time response was somewhat lower than at night but there is no evidence in any of the data for a marked inhibition of luminescence by light or for a daily rhythm. 
Having established the fact that the experimental techniques used had no appreciable effect on the luminescent response of Metridia, two more physiological experiments were performed. The first was designed to investigate an observation by the authors that animals which fed poorly still luminesced as vigorously as

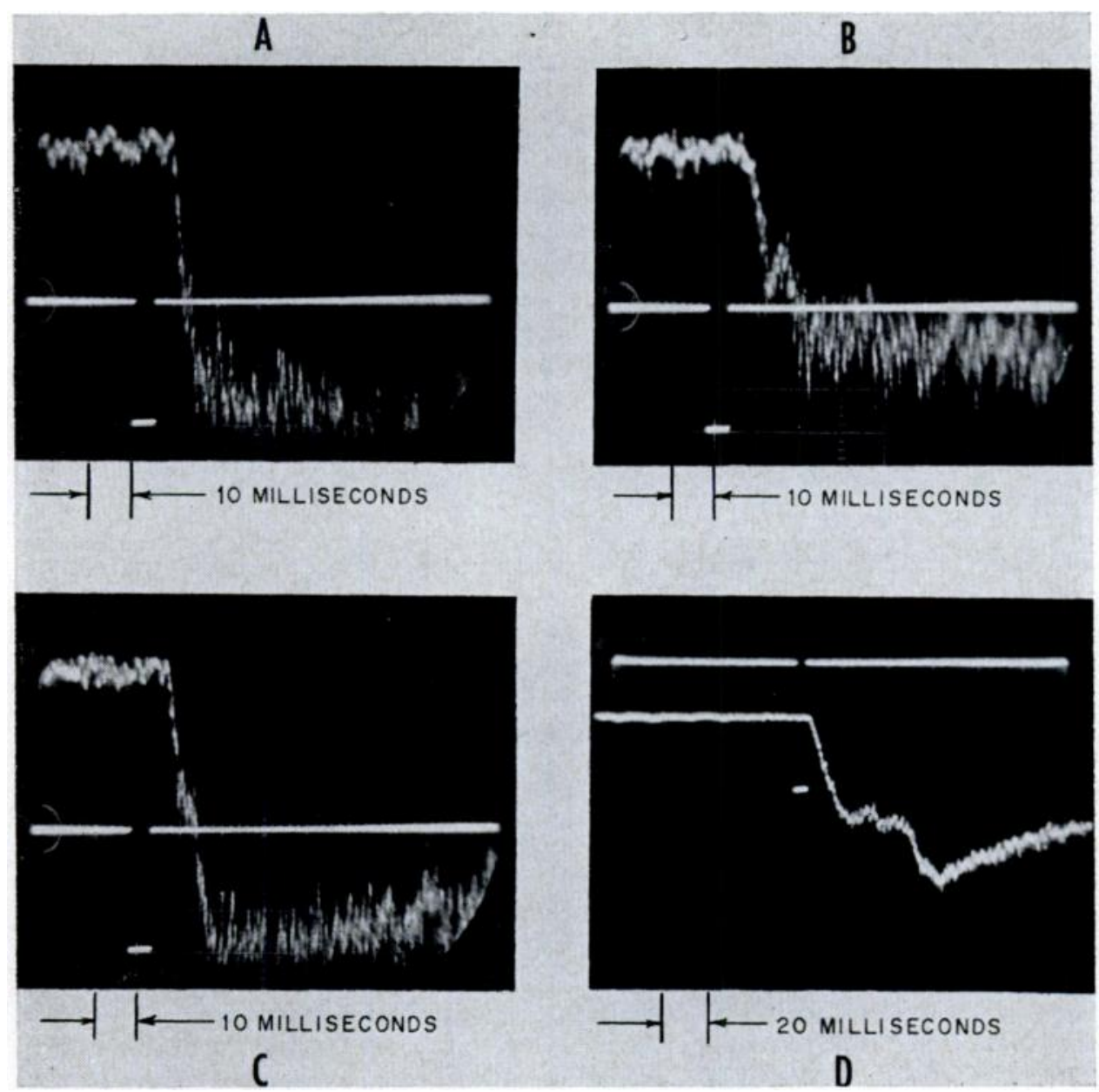

FIGURE 5. Lag time between stimulus and luminescent response. In all four cases the stimulus was 150 v. $/ 5$ msc. represented by the break in the smooth horizontal trace. Downward deflection of the jagged upper trace (lower trace in $D$ ) represents luminescence measured by the photomultiplier. The lag times were: $A, 8 \mathrm{msc}$; $B, 7 \mathrm{msc}$; $C, 8 \mathrm{msc}$. $D$ shows the same type of measurement but includes more of the intensity curve and the stepwise rise to maximum intensity.

animals that fed well. Two groups of animals were set up, one fed on the regular culture medium and the other starved in millipore-filtered sea water. After one week, single stimulus tests were performed. On the basis of the total area under the intensity $v s$. time curve, the results showed no difference between the two 
groups. However, when maximum intensity was considered, the results indicated statistically (Wilcoxen Ranked Sum) better luminescence for the starved group.

After the second week, repeated stimulus experiments were conducted on the two groups. Single stimulus data showed no statistical difference in the intensity of the response between the fed and starved groups, nor did the number of successive responses to repeated stimuli show a significant difference. At the end of the third week, however, experiments did demonstrate that the fed Metridia had a stronger luminescent response and the same group was able to respond to the electric stimulus a greater number of times than the starved animals.

In another series of experiments the length of time from the beginning of a stimulus to the beginning of a response (the lag time) was measured. For the necessary guidance and equipment to make these measurements, the authors are indebted to Dr. James F. Case at the Marine Biological Laboratory, Woods Hole, Mass. Single animals were tested in a small cell consisting of a $3-\mathrm{cm}$. piece of glass tubing with agar plugs and silver electrodes at either end. The electrodes were connected to a Grass S4 stimulator and the luminescence was measured with a RCA 931A photomultiplier in circuit with an oscilloscope. An automatic camera photographed the oscilloscope screen to record the results.

Using a stimulating pulse of $150 \mathrm{v}$. for 5 or $10 \mathrm{msc}$., the Metridia demonstrated a lag time (at room temperature) of 8-10 msc. to the beginning of the luminescent response and a lag time of 15-24 msc. to the maximum intensity of the response. The time to maximum intensity varied widely, depending on whether or not the rise to maximum intensity was direct or in a step-wise fashion, the latter giving lag times as long as 60 msc. (see Fig. 5). By observing the Metridia through a microscope during these experiments it was noticed that for a stimulus of 10 msc./150 v. usually both head and tail luminesced while for a stimulus of 5 msc. $/ 150 \mathrm{v}$. only the organs in the head region responded.

\section{Experiments on behavior}

Because it has often been suggested that luminescence functions as an escape mechanism for marine animals that luminesce by means of an extracellular discharge, the authors decided to investigate the behavior of Metridia in the presence of a predator. A series of experiments was conducted in the dark, in which possible planktonic predators on Metridia were placed individually with $10 \mathrm{Metridia}$ in 600-ml. beakers. The species tested were: Paraeuchaeta norvegica (Copepoda), Parathemisto (Euthemisto) gaudichaudii (Amphipoda), and euphausiids, Euphausia krohnii, Thysanoessa inermis, Nematoscelis megalops, and Meganyctiphanes norvegica.

Each experiment was continued for at least two days and counts of the number of Metridia present were made at intervals of 12 to 16 hours. Only in the case of the two euphausiids, Thysanoessa and Meganyctiphanes, was there any predation on the Metridia. Although not every individual tested fed on Metridia with the same rapacity, Meganyctiphanes was by far the most successful predator. The best predators among the animals tested were then chosen for further examination.

The predator was placed in a $600-\mathrm{ml}$. beaker with $10 \mathrm{Metridia}$ and this beaker was placed in the black box in front of the photometer. A cool water bath was used to keep the temperature in the experimental vessel between $10^{\circ}-12^{\circ} \mathrm{C}$. The 

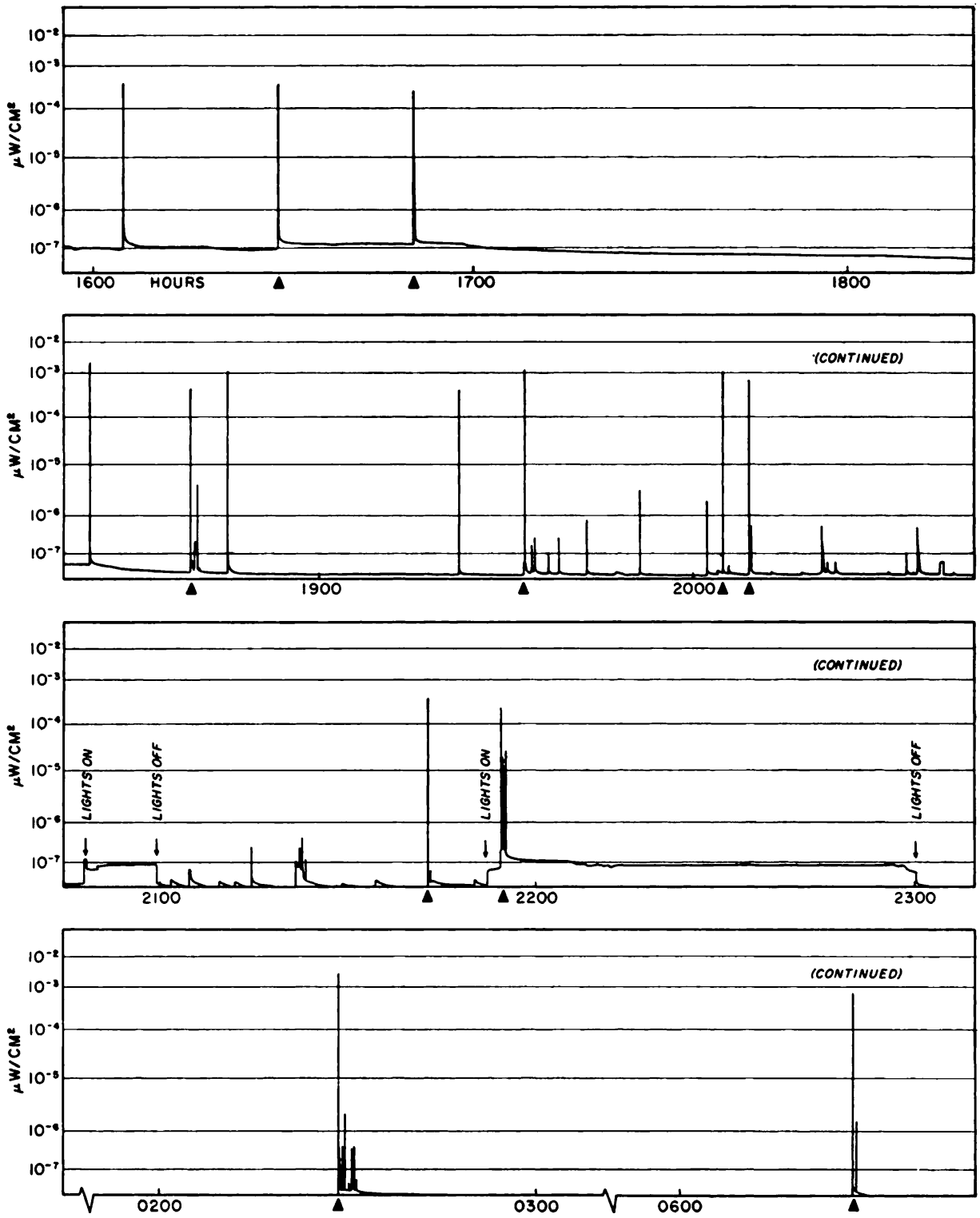

Figure 7. Record of behavior experiment 3 (see Table I). At the chart speed of $6 \mathrm{in} . / \mathrm{hr}$., luminescent flashes appear as spikes indicating maximum intensity and time of occurrence. Solid triangles indicate successful predation under interpretation outlined in text. The decreasing background intensity between 1600 and 1900 hours is due to the setting sun which reduced the ambient light in the laboratory. The increased background at 2045-2100 and 2150-2300 hours was caused by lights in the laboratory used to monitor the recorder. 
A sample record from an experiment with both prey and predator present is show in Figure 7. All the experiments are summarized in Table I. Experiments 6 and 7 in the table show quite clearly that the two species when separated from each other ordinarily do not produce any spontaneous luminescence. Only a single weak flash $\left(4 \times 10^{-7} \mu \mathrm{w} . / \mathrm{cm}^{2}\right)$, which may have been caused by some accidental mechanical stimulus, was observed for the group of Metridia alone. The Meganyctiphanes alone produced no luminescence at all. This corroborates Mauchline's (1959) observation that Meganyctiphanes does not luminesce spontaneously in the laboratory except during the breeding season (Dec.-Feb.). On the other

TABLE I

Summary of behavior experiments.

The table shows the interrelationship between luminescence and predation in Metridia lucens. For detailed explanation see text and Figure 8.

\begin{tabular}{|c|c|c|c|c|c|c|c|c|}
\hline \multirow{2}{*}{$\begin{array}{l}\text { Expt. } \\
\text { No. }\end{array}$} & \multirow{2}{*}{ Date } & \multirow{2}{*}{$\begin{array}{l}\text { Total } \\
\text { time } \\
\text { (hrs.) }\end{array}$} & \multicolumn{2}{|r|}{ Predator } & \multicolumn{2}{|c|}{ No. of Metridia } & \multicolumn{2}{|c|}{$\begin{array}{c}\text { Number of luminescent } \\
\text { responses }\end{array}$} \\
\hline & & & No. & Species & In expt. & Eaten & $\begin{array}{c}\text { Above 10-7 } \\
\mu \mathrm{w} . / \mathrm{cm}^{2}\end{array}$ & $\begin{array}{l}\text { Above 10-4 } \\
\mu \mathrm{w} . / \mathrm{cm} .^{2}\end{array}$ \\
\hline 1 & $8 / 12-13$ & 15 & 1 & Meganyctiphanes norvegica & 9 & 8 & 30 & 15 \\
\hline 2 & $8 / 17-18$ & 8 & 1 & Meganyctiphanes norvegica & 10 & 3 & 17 & 3 \\
\hline 3 & $9 / 14-15$ & 16 & 1 & Meganyctiphanes norvegica & 10 & 10 & 33 & 14 \\
\hline 4 & $9 / 16-17$ & 13.5 & 1 & Meganyctiphanes norvegica & 11 & 5 & 41 & 21 \\
\hline 5 & $9 / 18$ & 10.5 & 1 & Meganyctiphanes norvegica & 10 & 4 & 23 & 1 \\
\hline 6 & $8 / 13-14$ & 15.75 & - & - & 10 & 0 & 1 & $\mathbf{0}$ \\
\hline 7 & $8 / 14-15$ & 9.5 & 1 & Meganyctiphanes norvegica & $\mathbf{0}$ & - & $\mathbf{0}$ & $\mathbf{0}$ \\
\hline 8 & $8 / 11-12$ & 7.25 & 2 & Parathemisto gaudichaudii & 10 & 0 & 1 & $\mathbf{0}$ \\
\hline 9 & $8 / 19-20$ & 15.5 & 1 & Parathemisto gaudichaudii & 9 & 0 & $\mathbf{0}$ & 0 \\
\hline 10 & $8 / 18-19$ & 15.5 & 2 & Thysanoessa inermis & 10 & 1 & 3 & 0 \\
\hline 11 & $8 / 24-25$ & 15 & 1 & Nematoscelis megalops & 10 & 0 & 1 & 0 \\
\hline
\end{tabular}

hand, when the two species were placed in the same container, considerable luminescence was observed and some Metridia were eaten (experiments 1-5). Since most of the flashes showed up on the record as single spikes, some with an intensity greater than $10^{-4} \mu \mathrm{w} . / \mathrm{cm}^{2}$ (see Fig. 7 ), it was concluded that the copepod was primarily responsible for the display.

On the original records (copied in Fig. 7), it was possible to distinguish two kinds of single spikes, ones representing only a single luminescent flash and ones where several tracings were actually superimposed. This latter kind represented several flashes of different intensities which occurred within an interval short enough (30-40 seconds) to prevent their resolution at the slow chart speed. Sometimes this multiple-flash sequence was spread out over a longer period of time and the smaller flashes were resolved on the record (e.g. 0230 hours in Fig. 7). The number of multiple-flash sequences was, in almost every case, exactly equal to the number of Metridia eaten. These sequences presumably represent a Metridia's capture (large flash) and subsequent struggle to escape (small flashes). The 
remaining spikes on the record (caused by single flashes) are presumed to represent successful escapes by Metridia.

In order to determine if the mere mechanical disturbance of another organism in the container could cause luminescence, groups of Metridia were tested with several other species in the container placed in front of the photometer. A large Parathemisto (Euthemisto) gaudichaudii, a vigorously swimming hyperiid amphipod, did not induce any luminescence when placed with Metridia nor did it eat any (Table I, experiments 8 and 9). Similar results were obtained with the euphausiid Nematoscelis megalops (experiment 11). When Thysanoessa inermis was used (experiment 10) a few flashes were produced and a single Metridia was eaten during the experiment. A further test of the effect of mechanical stimulation was made by vigorously stirring the water in a beaker containing Metridia. Considerable disturbance was necessary before any flashing occurred and even the most energetic agitation elicited a maximum response of only $6 \times 10^{-5} \mu \mathrm{w} . / \mathrm{cm} .{ }^{2}$, less than one tenth of the highest responses shown in Table I and Figure 7.

Direct observation of predation was also attempted in order to determine the nature of the luminescence stimulus. An infra-red-sensitive "sniper-scope" (Edmund Scientific Co.) was used with the infra-red source and a focusing lens placed behind the experimental beaker so that the animals appeared in opaque profile against a light background. The small Metridia were not always visible with this optical arrangement but some individuals were seen to be carried toward the euphausiid by the currents set up by the larger animal's pleopods. Sometimes the Metridia would dart away before reaching the Meganyctiphanes, but at other times the copepod would seem to come in contact with the euphausiid before darting away. On a few occasions the euphausiid started off as though in pursuit, but the actual act of capture was never observed.

These observations are in general agreement with those of Mauchline (1959) who found Meganyctiphanes capable of filter-feeding on organic detritus and even sucking into the "food basket" individual copepods (Paraeuchaeta norvegica) and Sagitta by lateral-ventral movements of the thoracic limbs. The animal can also seize larger objects by raptorial movements of the appendages but in the laboratory "no hunting or stalking of prey takes place" (Mauchline, 1959).

\section{Discussion}

Over the years there has been considerable speculation regarding the role of bioluminescence in the life of various marine organisms. In higher marine forms, luminescence has been found associated with either mating behavior, feeding mechanisms, or defense. Among planktonic species, however, there is less agreement as to its functional significance. Besides the three interpretations given above, it has been suggested that this phenomenon may often be coupled with other life processes in lower animals and therefore might have no function of its own (Russell and Yonge, 1928; Harvey, 1929). It has also been suggested that luminescence in planktonic and sessile creatures may serve as a "burglar alarm," thereby revealing a predator to its own enemies along the food chain (Burkenroad, 1943).

From the results of the behavior experiments with Metridia, it is apparent that there is some relationship between luminescence and the act of predation. Since the exact nature of the stimulus is still unknown, it is impossible to determine 
positively which, if any, of the above hypotheses is applicable. Nevertheless, some of the possibilities may be eliminated.

Any functional use of luminescence involving species recognition, such as mating display or warning systems to other individuals of danger, is doubtful because Metridia probably does not have an adequate image-forming eye. Of the remaining speculations presented above, the authors currently feel that the defense mechanism is the one most consistent with the experimental results. However, Burkenroad's hypothesis is not specifically ruled out.

The reasons for favoring the idea of an escape mechanism arise from: (1) certain of the physical and physiological characteristics of Metridia's luminescent emission, and (2) a unique pattern of behavior associated with luminescence in this copepod.

The maximum intensity of Metridia's luminescence is surprisingly brilliant. At the working distance $(18 \mathrm{~cm}$.) used in this study the flash was of the same order of magnitude as that of certain coelenterates and of the crustacean Euphausia pacifica, and greater than that of the teleost Myctophum punctatum, all measured at $1 \mathrm{~cm}$. (Nicol, 1960). The duration of the flash is long and its spectral composition is similar to the spectrum of the transmission of light through sea water with the maximum of the two curves at nearly the same wave-length. It has also been shown that Metridia has an extremely short lag time between stimulus and response. The animal recovers quickly after stimulation and fatigues rather slowly on repeated stimulation, even after several weeks without food, suggesting that the ability to luminesce is important enough to the organism to be maintained under adverse conditions. All these characteristics of Metridia's luminescence, both physical and physiological, would certainly be selectively advantageous to the animal if its luminescence functioned as an escape mechanism.

The most significant evidence for the defense mechanism hypothesis, however, comes from observations of the behavior of single Metridia stimulated in the electrode chamber. On stimulation a point of luminescence was immediately produced and then in the majority of cases the animal appeared to dart off into the dark, leaving a bright luminescent spot at its original position and sometimes a trail of tiny luminescent specks that soon disappeared. Although the animal itself could not be seen during this reaction, the agitation of the water gave a clue to its behavior and its new position could be verified by passing a second electrical stimulus through the water and observing the new location of the resulting luminescent flash. The original luminescent emission remained a more or less discrete point of light for some seconds after stimulation.

Such a behavior pattern appears to the authors to indicate the manner in which Metridia escapes from Meganyctiphanes. Although the precise role that luminescence plays in this escape mechanism is still unknown, two speculations are possible. The luminescent emission may startle the attacker, interrupting its feeding procedure, or it may merely function as an attractive decoy. In either case, the Metridia's rapid departure from the spot where it had luminesced would complete the escape.

The possibility that luminescence only occurs when the Metridia is actually captured is not entirely eliminated. More definitive proof must await the elucidation of the specific stimulus that induces luminescence. Nevertheless the evidence pre- 
sented here indicates that luminescence functions on the behavioral level as an escape mechanism for Metridia. It would then seem probable that luminescence, which is of such widespread occurrence in the oceans, may well have survival value in defense against predation in some similar manner for many other animals of the plankton.

\section{SUMMARY}

1. Skin glands believed to be the source of luminescence were found on the anterior portion of the head, on the last thoracic segment, and on the posterior margins of each segment of the abdomen.

2. The maximum intensity of the luminescent flash was $1.2 \times 10^{-3} \mu \mathrm{w} . / \mathrm{cm} .^{2}$ (at $18 \mathrm{~cm}$.). The flash rose rapidly to peak intensity and then decayed slowly. The total duration of the flashes with peaks greater than $10^{-4} \mu \mathrm{w} . / \mathrm{cm} .^{2}$ ranged from 3 to 50 seconds.

3. The peak of the luminescence spectrum occcurred at $482 \mathrm{~m} \mu$ and the curve fell off to one-half the maximum value at $440 \mathrm{~m} \mu$ and $525 \mathrm{~m} \mu$.

4. The ability of Metridia to luminesce on stimulation was found to be largely unaffected by prolonged laboratory culture. Starvation had little effect on the luminescence for the first three weeks and there was never any inhibition by previous light- or dark-adaptation.

5. With an increase in the strength of the electric stimulus from $0.3 \mathrm{amp}$. to 0.7 amp., the intensity of the luminescent flash was found to increase. With pulses stronger than 0.7 amp. no change in intensity was recorded but the number of successive responses to repeated stimuli was reduced. Duration of the pulse had little effect on the intensity or the number of successive responses.

6. Metridia showed a lag time of 8-10 msc. to the beginning of the luminescent response. The lag time to the peak of the luminescent response varied from 20 to $60 \mathrm{msc}$.

7. There was no spontaneous luminescence produced by groups of Metridia under conditions of constant darkness. However, the presence of certain planktonic predators, most notably Meganyctiphanes norvegica, caused a brilliant display of luminescence. The number of flashes attributable to Metridia was always greater than the number of Metridia eaten by the predator. There was little evidence that the luminescent euphausiid, Meganyctiphanes, flashed spontaneously either in the presence or absence of its prey.

8. Observations on the behavior of Metridia during and just after luminescence suggest that the flashing may be involved in an escape mechanism, but the precise effect of the light on the predator has not been determined.

\section{LITERATURE CITED}

Bigelow, H. B., 1924. Plankton of the offshore waters of the Gulf of Maine. Bull. U. S. Bur. Fish., 40 : pt. II, 509 pp.

Boden, B. P., AND E. M. Kampa, 1957. Records of bioluminescence in the ocean. Pacific Sci., 2: 229-235.

Boden, B. P., AND E. M. KAmpa, 1958. Lumière, bioluminescens et migrations de la couche diffusante profande en Méditerranée occidentale. Vie et Milieu, 9: 1-10.

BoecK, A., 1865. Oversigt over de ved Norges kyster iagttage Copepoder henhorende til Calanidernes Cyclopidermes og Harpactidernes familier. Forh. Vidensk. Selsk. Krist., 7: 226-282. 
Breslau, L. R., 1959. The portable bathyphotometer. Unpublished manuscript. Reference No. 59-28, Woods Hole Oceanographic Institution.

Breslau, L. R., and H. E. Edgerton, 1958. The luminescence camera. J. Biol. Photogr. Assoc., 26 : 49-58.

Burkenrond, M. D., 1943. A possible function of bioluminescence. J. Mar. Res., 5: 161-164.

Clarke, G. L., 1933. Diurnal migration of plankton in the Gulf of Maine and its correlation with changes in submarine irradiation. Biol. Bull., $65: 402-436$.

Clarke, G. L., 1934. Further observations on the diurnal migration of copepods in the Gulf of Maine. Biol. Bull., 67 : 432-455.

Clarke, G. L., 1954. Elements of Ecology. John Wiley and Sons, New York.

Clarke, G. L., AND R. H. Backus, 1956. Measurements of light penetration in relation to vertical migration and records of luminescence of deep-sea animals. Deep-Sea Res., 4: 1-14.

Clarke, G. L., And L. R. Breslau, 1959. Measurements of bioluminescence off Monaco and Northern Corsica. Bull. Inst. Oceanogr., Monaco, 56: (1147) : 31 pp.

Clarke, G. L., and L. R. Breslau, 1960. Studies of luminescent flashing in Phosphorescent Bay, Puerto Rico, and in the Gulf of Naples using a portable bathyphotometer. Bull. Inst. Oceanogr. Monaco, 57 (1171) : 32 pp.

Clarke, G. L., and C. J. Hubbard, 1959. Quantitative records of the luminescent flashing of oceanic animals at great depths. Limnol. Oceanogr., 4: 163-180.

Clarke, G. L., and G. K. Wertheim, 1956. Measurements of illumination at great depths and at night in the Atlantic Ocean by means of a new bathyphotometer. Deep-Sea Res., 3: 189-205.

Dahl, F., 1893. Pleuromma, ein Krebs mit Leuchtorgan. Zool. Anz., 16: 104-109.

DAнl, F., 1894. Leuchtende Copepoden. Zool. Anz., 17 : 10-13.

Farra N, G. P., 1920. On the local and seasonal distribution of the pelagic Copepoda of the southwest of Ireland. Publ. Circ., Cons. Perm. Int. Explor. Mer, No. 73, 30 pp.

Giesbrecht, W., 1895. Uber das Leuchten der pelagischen Copepoden und das tierische Leuchten in allgemeinen. Mitt. Zool. Sta. Neapel, 11: 631-694.

Harvey, E. N., 1929. Phosphorescence. Encyclopedia Brittanica, 14th ed., p. 117.

Harvey, E. N., 1952. Bioluminescence. Academic Press, New York.

KAMPA, E. M., AND B. P. Boden, 1957. Light generation in a sonic-scattering layer. DeepSea Res., 4 : 73-92.

Kiernik, E., 1908. Uber einige bisher unbekannte leuchtende Tiere. Zool. Anz., 33: 376-380.

Lowe, E., 1935. The anatomy of a marine copepod Calanus finmarchicus (Gunnerus). Trans. Roy. Soc. Edinb., 58: 561-603.

Mauchline, J., 1959. The biology of the euphausiid crustacean, Meganyctiphanes norvegica (M. Sars). Proc. Roy. Soc. Edinb., 67: 141-179.

Nicol, J. A. C., 1960. The Biology of Marine Animals. Sir Isaac Pitman, London.

Russell, F. S., ANd C. M. Yonge, 1928. The Seas. Frederick Warne, London.

Sewell, R. B. S., 1932. The Copepoda of Indian seas. Calanoida. Mem. Indian Mus., 10: 407 pp.

Sewell, R. B. S., 1947. The free-swimming planktonic Copepoda. Systematic account. Sci. Repts., John Murray Expd., 8 : 303 pp.

Vanhöffen, E., 1895. Das Leuchten von Metridia longa Lubb. Zool. Anz., 18: 304-305. 